\title{
Child penalties across industries: why job characteristics matter
}

\section{Sébastien Fontenay, Thomas Murphy \& Ilan Tojerow}

To cite this article: Sébastien Fontenay, Thomas Murphy \& Ilan Tojerow (2021): Child penalties across industries: why job characteristics matter, Applied Economics Letters, DOI: 10.1080/13504851.2021.1994518

To link to this article: https://doi.org/10.1080/13504851.2021.1994518

\section{1.}

Submit your article to this journal $\square$

Q View related articles ¿

View Crossmark data 


\title{
Child penalties across industries: why job characteristics matter
}

\author{
Sébastien Fontenay $\left(\mathbb{D D}^{\mathrm{a}}{ }^{\mathrm{a}}\right.$, Thomas Murphy ${ }^{\mathrm{b}}$ and Ilan Tojerow \\ ${ }^{a} S B S-E M$, DULBEA, CEBRIG, Université Libre de Bruxelles, Brussels, Belgium; 'bSBS-EM, DULBEA, Université Libre de Bruxelles, Brussels, Belgium; \\ 'SBS-EM, DULBEA, CEBRIG \& IZA-Bonn, Université Libre de Bruxelles, Brussels, Belgium
}

ABSTRACT

This article investigates the impact of parenthood on women's labour market outcomes in Belgium. Using administrative data and an event study design, we show that mothers lose $32 \%$ of their labour earnings relative to fathers, up to eight years after the birth of their first child. Furthermore, we find a strong positive correlation between the size of the child penalty for a given sector and the share of its workers who report working atypical work schedules or irregular hours, suggesting that job characteristics matter in determining the size of the child penalty.
KEYWORDS

Motherhood; child penalty; labour earnings; industries; working conditions

JEL CLASSIFICATION

$\mathrm{J} 13 ; \mathrm{J} 16 ; \mathrm{J} 22$

\section{Introduction}

A growing body of literature shows how motherhood is detrimental to women's professional careers (e.g. Kleven, Landais and Søgaard 2019; Rosenbaum 2021). Estimates from different countries suggest that the reduction in women's earnings relative to men due to having become a parent - the so-called child penalty ranges between 20 and $60 \%$ (Kleven, Landais, Posch, Steinhauer and Zweimüller 2019). Ample cross-country variation indicates that social norms, especially attitudes towards working mothers, play an important role (Kleven, Landais, Posch et al. 2019). For this reason, several papers have looked into the implementation of family policies, among which paternity leave, liable to reduce the gender earnings gap, with mixed results (e.g. Arnarson and Mitra 2010; Ekberg, Eriksson, and Friebel 2013).

We take another approach and look instead at how child penalties vary across industries within a given country, Belgium. Using administrative registers covering the last two decades, we estimate the nationwide child penalty and compare the career arcs of women who were working in different sectors prior to the birth of their first child. We anticipate that child penalties will vary with mothers' ability to balance work and family demands and hence with job characteristics. If a sector is characterized by working conditions that make it more difficult to achieve such a balance, we expect new mothers working in that sector to become more likely to adapt their labour supply. While previous research has highlighted how motherhood creates incentives to switch to the public sector (Kleven, Landais and Søgaard 2019), we argue that women may also be limited in their sectoral mobility because they have acquired specific human capital or work experience. Our empirical design helps capture all of these dynamic mechanisms and sheds light on the long-run consequences of premotherhood choices.

Our event study analysis is the first of its kind conducted in Belgium. We show that mothers lose $32 \%$ of their labour earnings relative to fathers, up to eight years after the birth of their first child. Interestingly, we find a strong positive correlation between the size of the child penalty for a given sector and the share of its workers who report working atypical work schedules or irregular hours. This evidence, while not necessarily causal, lends credence to our argument that job characteristics matter and that mothers employed in sectors offering poor work-family balance are more likely to suffer an important child penalty.

CONTACT Sébastien Fontenay sebastien.fontenay@ULB.BE S SBS-EM, DULBEA, CEBRIG, Université Libre de Bruxelles, Avenue F.D. Roosevelt, 50, Brussels 1050, Belgium

๑ 2021 Informa UK Limited, trading as Taylor \& Francis Group 


\section{Data and methodology}

We exploit data from administrative registers with quarterly information on labour market history. Importantly, we can match children with their parents, as well as parents with their employer.

We narrow our sample to all individuals who had their first child between 2002 and 2013, leaving us with an estimation sample of 356,120 first-time mothers and 326,591 first-time fathers, whom we follow over a period of up to 12 years, from 4 years prior to the birth of their first child to 8 years after. ${ }^{1}$

We estimate the impact of children on labour market outcomes using the event study approach of Kleven, Landais and Søgaard (2019), who argue that while fertility choices are not exogenous, the event of becoming a parent causes sudden changes in labour market outcomes that are orthogonal to unobserved determinants. The causal interpretation of the results relies on the so-called smoothness assumption, which states that, absent the shock resulting from the birth of their first child, parents' outcomes would evolve smoothly over time.

Our event study design exploits quarterly variation in the timing of first births at the individual level. For each individual we denote by $t=0$ the quarter-year in which their first child was born, and we index all quarters relative to that quarter. We then estimate the following equation separately for men and women:

$$
\begin{aligned}
Y_{i y q t}^{g}= & \sum_{j \neq-4} \beta_{j}^{g} \cdot I[\mathrm{j}=\mathrm{t}]+\sum_{k} \gamma_{k}^{g} \cdot I\left[\mathrm{k}=a g e_{i y q}\right] \\
& +\sum_{l} \delta_{l}^{g} \cdot I[\mathrm{l}=\mathrm{yxq}]+ \\
\in_{i q t}^{g} &
\end{aligned}
$$

where $Y_{\text {iyqt }}^{g}$ represents the outcome of interest for individual $i$ of sex $g$ in year $y$ and quarter $q$ at event time $t$. On the right-hand side, equation (1) includes a full set of event time dummies (first term). We omit the event time dummy at $t$ $=-4$, implying that the event time coefficients $\beta_{j}^{g}$ measure the impact of having children relative to four quarters prior to the birth of the first child. Equation (1) also includes age dummies (second term) and time period dummies (third term) to control nonparametrically for underlying life cycle trends, as well as time trends and seasonal effects.

To convert level effects into percentage effects, we then divide - for each sex and at event time $t$ the estimated event time coefficients by the predicted labour income net of the event time dummies:

$$
P_{t}^{g}=\frac{\hat{\beta}_{t}^{g}}{E\left(\tilde{Y}_{\text {iyqt }}^{g} \mid t\right)}
$$

Finally, we calculate the child penalty at event time $t$ as:

$$
P_{t}=\frac{\hat{\beta}_{t}^{m e n}-\hat{\beta}_{t}^{\text {women }}}{E\left(\tilde{Y}_{i y q t}^{\text {women }} \mid t\right)}
$$

The child penalty thus calculated represents the average percentage by which mothers' earnings are lower relative to fathers' due to having become a parent.

\section{Impact of children on mothers' careers}

Figure 1 plots the sex-specific impacts of becoming a parent $\left(P_{t}^{\text {men }}\right.$ and $\left.P_{t}^{\text {women }}\right)$ across event time $t$ for four outcome variables, for the whole of Belgium. As can be seen in Panel A, the quarterly gross labour earnings of men and women evolve in parallel until childbirth, before diverging sharply.

During the quarter in which women give birth to their first child $(t=0)$, they see their labour earnings reduced by about $60 \%{ }^{2}$ A year later $(t=4)$, their labour earnings remain lower by $19 \%$. We observe a second drop between $t=4$ and $t=11$, attributable to mothers who go on to have more children. As of $t=12$, mothers' estimated earnings loss stabilizes. The long-run child penalty - the average percentage by which women are falling behind men due to children across event times 24 to 32 - is equal to $32 \%$.

Comparing our estimated long-run child penalty with those for other countries by Kleven, Landais, Posch et al. (2019), we observe that Belgium is

\footnotetext{
${ }^{1}$ Since we follow parents over the period 2002-2016, our panel is unbalanced.

${ }^{2}$ The loss in labour income is partially compensated by maternity leave benefits $-82 \%$ of pre-leave income - as shown on Figure A1 in the Appendix.
} 

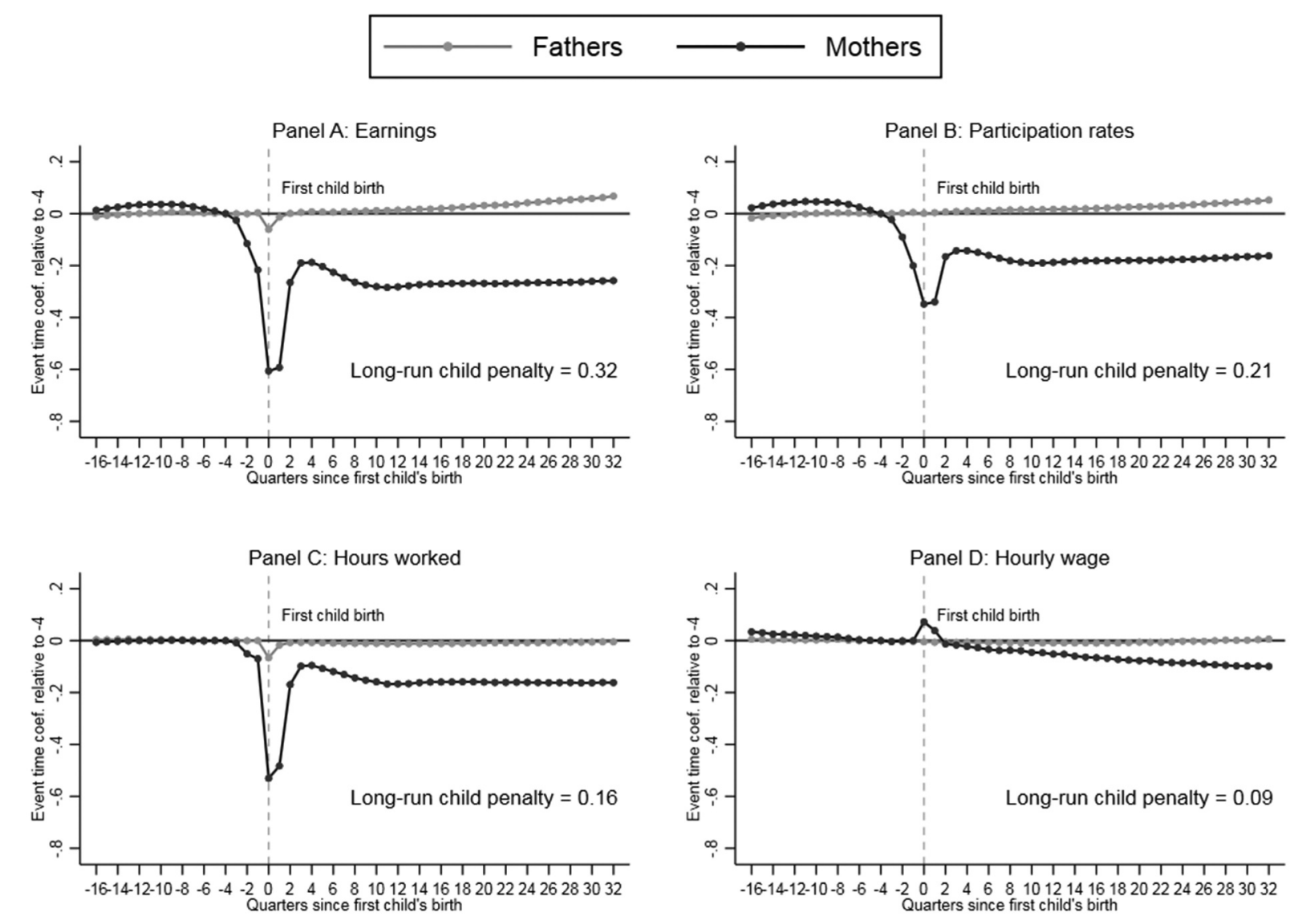

Figure 1. Impacts of children. Note: The shaded 95\% confidence intervals are based on robust standard errors. Hours worked (Panel C) and hourly wages (Panel D) are estimated conditional on labour market participation and employee status.

closer to English-speaking countries (around 37\%) than to German-speaking countries (around 55\%) or Scandinavian countries (around 25\%).

Following Sieppi and Pehkonen (2019), we also construct a new measure of earnings that accounts for social security transfers, including allowance for maternal/paternal leave and child benefits. Figure A1 in the Appendix reveals that the long-term child penalty remains substantial, with a gap of $19 \%$ between mothers and fathers.

The estimated child penalty in earnings has several potential explanations. Panel B shows that women are likelier than men to leave the labour market after having become a parent; we estimate a long-run child penalty in labour force participation of $21 \%$. Panel $\mathrm{C}$ shows that the women who remain tend to reduce the number of hours they work; our estimated long-run child penalty is of $16 \%$. Finally, Panel D suggests another penalty in the form of a reduction in hourly wage of about $9 \%$. The reason that child penalties are visible as of $t=$
-3 is that some women enter sick leave prior to childbirth, due to pregnancy-related health issues (Fontenay and Tojerow 2020).

\section{Child penalties across pre-birth sectors of employment}

To shed light on the mechanisms that result in mothers suffering large child penalties, we now run our model by sector of employment prior to entry into motherhood. Previous research has explored the interaction between parenthood and gender gaps across particular occupations, including pharmacists (Goldin and Katz 2016), young professionals in the financial and corporate sectors (Bertrand, Goldin, and Katz 2010), as well as highearners who hold an MBA, law or STEM degree (Bütikofer, Jensen, and Salvanes 2018), highlighting the role of nonlinear wage structures and the returns to long working hours (de Quinto, Hospido, and Sanz 2021). We complement these 


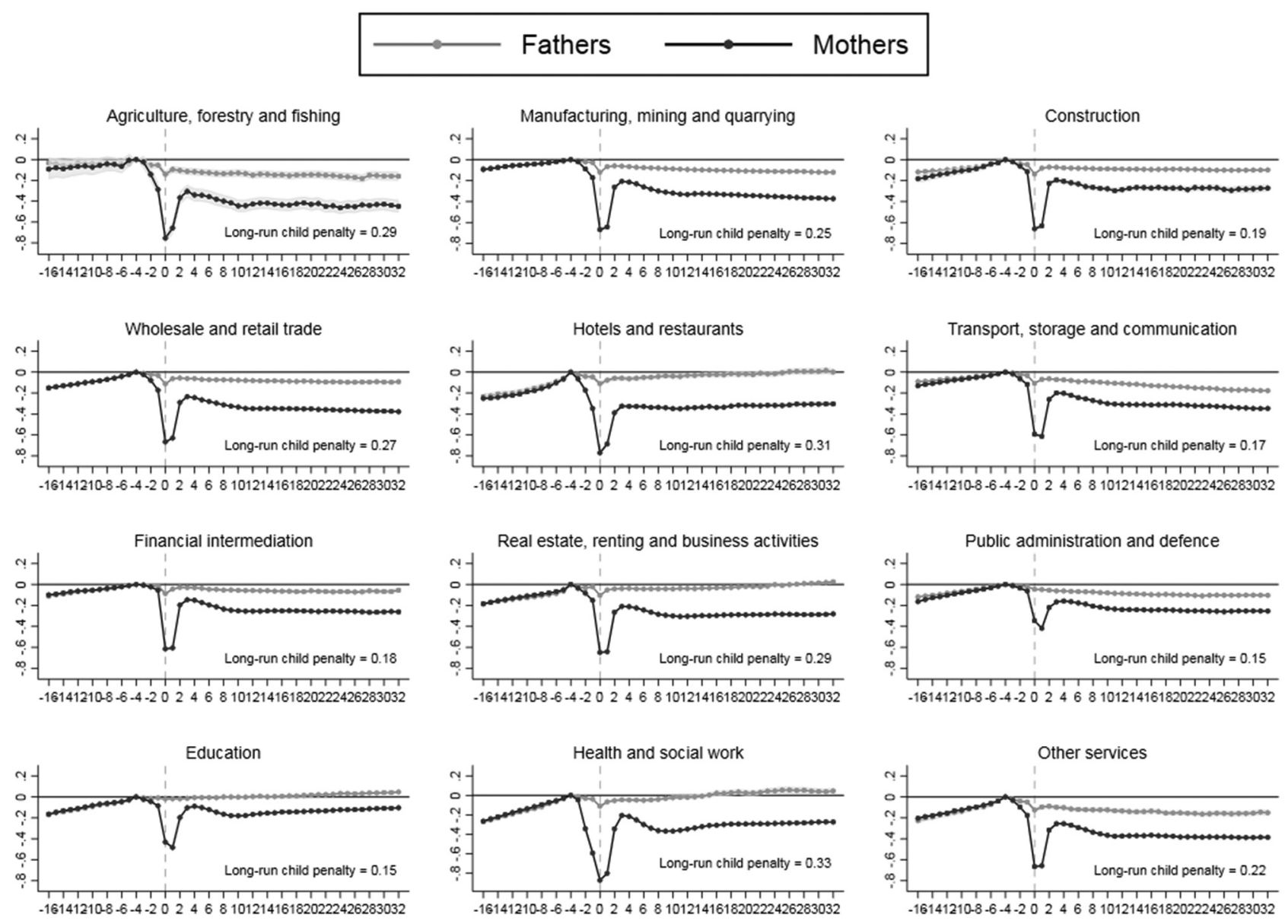

Figure 2. Impacts of children by sector of employment. Note: The shaded 95\% confidence intervals are based on robust standard errors. Under 'Other services', we group activities that fall into sections R, S T and U of NACE Rev. 2.

findings by providing what is, to our knowledge, the first systematic measure of child penalties across industries, using the well-established NACE classification of economic activities. In addition, we explore the drivers of the large differences in penalties observed across sectors, with a particular focus on working conditions.

One could argue that women self-select into specific sectors and therefore that sector-specific child penalties reflect inherent differences between parents. However, we argue that women do not fully anticipate the costs of motherhood and that they make employment decisions that do not account completely for the future costs of having children. This is compatible with the findings of Kuziemko et al. (2018), who show that women are over-optimistic about their postchildbirth working life.
Figure 2 shows the sex-specific impacts of becoming a parent for gross labour earnings by pre-birth sector of employment. ${ }^{3}$ These show that the amplitude of the child penalty varies significantly across NACE sectors: for sectors such as hospitality or health, the estimated long-run child penalties are above $30 \%$, while for other sectors, such as education or public administration, the child penalties are closer to $15 \%$.

We posit that a substantial part of the variation in the size of the child penalty across employment sectors stems from the nature of the work and of the demands that it places on mothers. Since women assume a larger share of childcare-related activities (Guryan, Hurst, and Kearney 2008), it is expected that they should be more likely to adapt their labour supply if they have a job where balancing work and family life is more difficult. This

\footnotetext{
${ }^{3}$ The new sample is conditional on being salaried employee in a given sector at $t=-4$. It comprises 202,195 first-time mothers and 201,496 first-time fathers.
} 
would explain why a sector such as education, where working hours and holidays are well established, has a child penalty that is half that of the hospitality industry, where evening and weekend shifts are the norm and schedules change weekly.

To lend credence to our hypothesis, we use data from the European Working Conditions Survey (EWCS) to correlate worker-reported sector characteristics with our estimated longrun child penalties. The results are presented in Figure 3: they show a clear positive correlation between the size of the child penalty for a given sector and the share of its workers who report poor work-life balance (Panel A), working with atypical schedules (Panels $\mathrm{B}$ and $\mathrm{C}$ ) or irregular hours (Panel D). It appears that women who work in sectors where balancing family life and work is more complicated do indeed suffer higher penalties as a result of having become a parent.
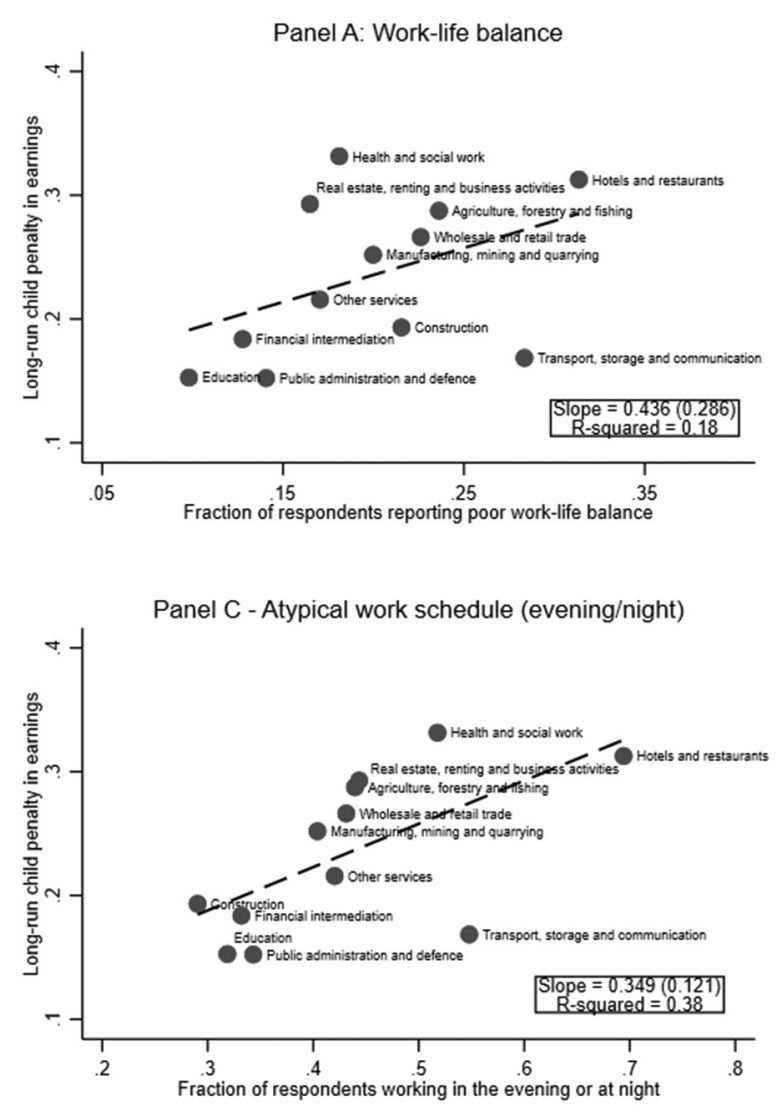

In a final exercise, we explore how the long-run child penalty relates to the gender gap in earnings. First, we correlate our estimates of child penalties across sectors to the existing gender gap before the birth of the first child (that is, $t=-4$ in the event study design). Panel A of Figure A2 in the Appendix shows that women earn on average $15 \%$ less than men prior to parenthood, with little variation across sectors and no clear correlation with the future child penalty. In comparison, Panel B of Figure A2 reveals ample variation when the whole sample is considered (i.e. all workers, at any stage of family formation). It is particularly interesting to see that some sectors that had comparable pre-birth gender gaps, such as the health or education sectors, display important divergences when all periods are considered. In fact, we observe that the gender wage gap now strongly correlates with our estimated long-run child penalty (with an R-squared equal to $42 \%$ ).
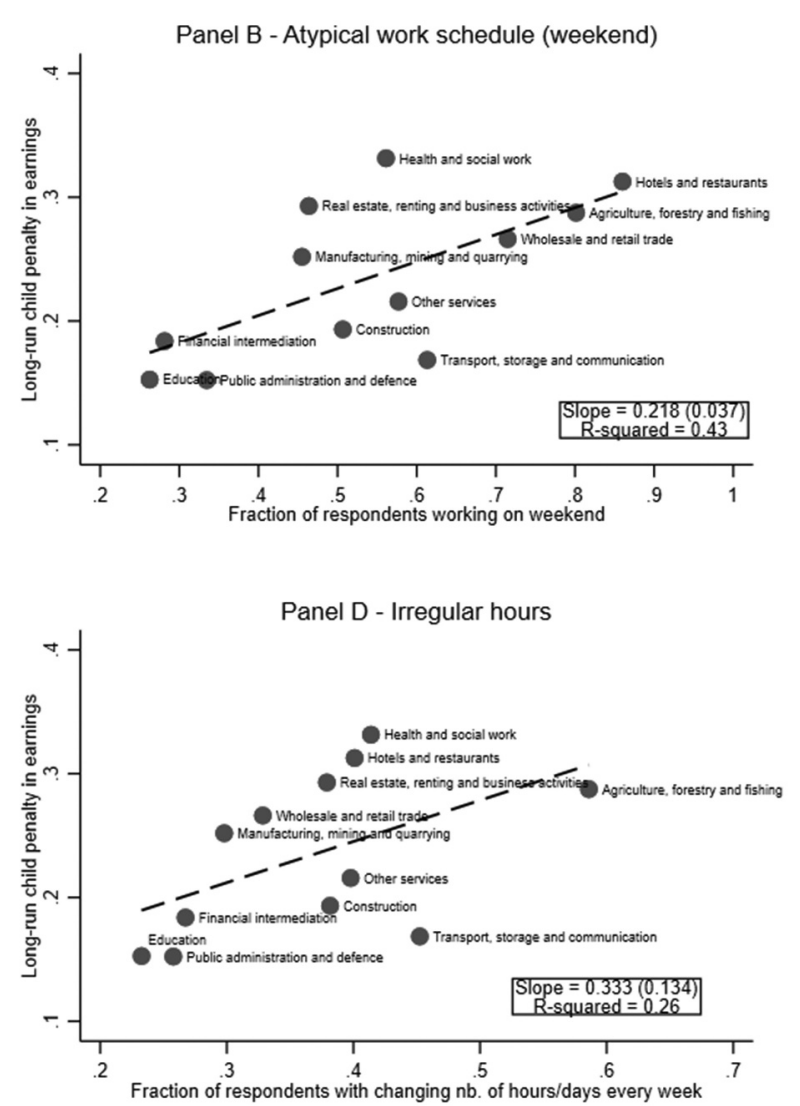

Figure 3. Long-run child penalties and worker-reported sector characteristics. Notes: The $x$-axes show the fraction of respondents to the EWCS who answer 'not very well' or 'not at all well' to question Q41 (Panel A), 'at least once' to Q34 and/or Q35 (Panel B),"at least once" to Q32 and/or Q33 (Panel C) and 'Yes' to Q37b and/or Q37c (Panel D). The figures also display a linear trend, whose slope is reported with standard errors in parentheses. 
We believe that these results confirm the importance of the role played by parenthood in determining the labour outcomes of women relative to men, suggesting that the way in which specific occupations enable workers to deal with the consequences of parenthood is key in explaining the gender gaps in earnings across sectors.

\section{Conclusion}

Using an event study analysis, we look at how child penalties vary across employment sectors in Belgium. We first calculate a long-run child penalty in earnings of $32 \%$, which puts Belgium in the same league as the USA and the UK, and find that the size of the child penalty varies from $15 \%$ for the education and public sectors to over $30 \%$ for the hospitality and health sectors. We then correlate worker-reported sector characteristics with sector-specific child penalties and find that sectors where maintaining a healthy work-life balance is more difficult also present higher child penalties.

Our findings provide evidence that job characteristics matter in determining the size of the child penalty and can be related to Goldin's (2014) argument that successfully reducing gender inequality might not always require government intervention and evolution in social norms, which is necessarily slow. Rather, changes in the labour market, especially in the structure of jobs and in the possibility that they offer of balancing work and family life, could play an important role. Our results suggest that the child penalty could be lowered in some sectors that disproportionately reward working atypical or irregular hours.

\section{Disclosure statement}

No potential conflict of interest was reported by the author(s).

\section{ORCID}

Sébastien Fontenay (D) http://orcid.org/0000-0003-2279-5660

\section{References}

Arnarson, B. T., and A. Mitra. 2010. "The Paternity Leave Act in Iceland: Implications for Gender Equality in the Labour Market." Applied Economics Letters 17 (7): 677-680. doi:10.1080/13504850802297830.

Bertrand, M., C. Goldin, and L. F. Katz. 2010. "Dynamics of the Gender Gap for Young Professionals in the Financial and Corporate Sectors." American Economic Journal: Applied Economics 2 (3): 228-255.

Bütikofer, A., S. Jensen, and K. G. Salvanes. 2018. "The Role of Parenthood on the Gender Gap among Top Earners." European Economic Review 109: 103-123. doi:10.1016/j. euroecorev.2018.05.008.

de Quinto, A., L. Hospido, and C. Sanz (2021). "The Child Penalty: Evidence from Spain.” SERIEs.

Ekberg, J., R. Eriksson, and G. Friebel. 2013. "Parental Leave - A Policy Evaluation of the Swedish "Daddymonth" Reform." Journal of Public Economics 97 (C): 131-143. doi:10.1016/j.jpubeco.2012.09.001.

Fontenay, S., and I. Tojerow. 2020. "Work Disability after Motherhood and How Paternity Leave Can Help." IZA Discussion Paper (13756).

Goldin, C. 2014. "A Grand Gender Convergence: Its Last Chapter.” American Economic Review 104 (4): 1091-1119. doi:10.1257/aer.104.4.1091.

Goldin, C., and L. F. Katz. 2016. “A Most Egalitarian Profession: Pharmacy and the Evolution of A Family-Friendly Occupation." Journal of Labor Economics 34 (3): 705-746. doi:10.1086/685505.

Guryan, J., E. Hurst, and M. Kearney. 2008. "Parental Education and Parental Time with Children." Journal of Economic Perspectives 22 (3): 23-46. doi:10.1257/ jep.22.3.23.

Kleven, H., C. Landais, J. Posch, A. Steinhauer, and J. Zweimüller. 2019. "Child Penalties across Countries: Evidence and Explanations." AEA Papers and Proceedings 109: 122-126. doi:10.1257/pandp.20191078.

Kleven, H., C. Landais, and J. E. Søgaard. 2019. "Children and Gender Inequality: Evidence from Denmark." American Economic Journal: Applied Economics 11 (4): 181-209.

Kuziemko, I., J. Pan, J. Shen, and E. Washington. 2018. “The Mommy Effect: Do Women Anticipate the Employment Effects of Motherhood?" National Bureau of Economic Research Working Paper Series(24740).

Rosenbaum, P. 2021. "Pregnancy or Motherhood Cost? A Comparison of the Child Penalty for Adopting and Biological Parents." Applied Economics 53 (29): 3408-3422. doi:10.1080/00036846.2021.1881431.

Sieppi, A., and J. Pehkonen. 2019. "Parenthood and Gender Inequality: Population-based Evidence on the Child Penalty in Finland." Economics Letters 182: 5-9. doi:10.1016/j.econlet.2019.05.034. 


\section{Appendix}

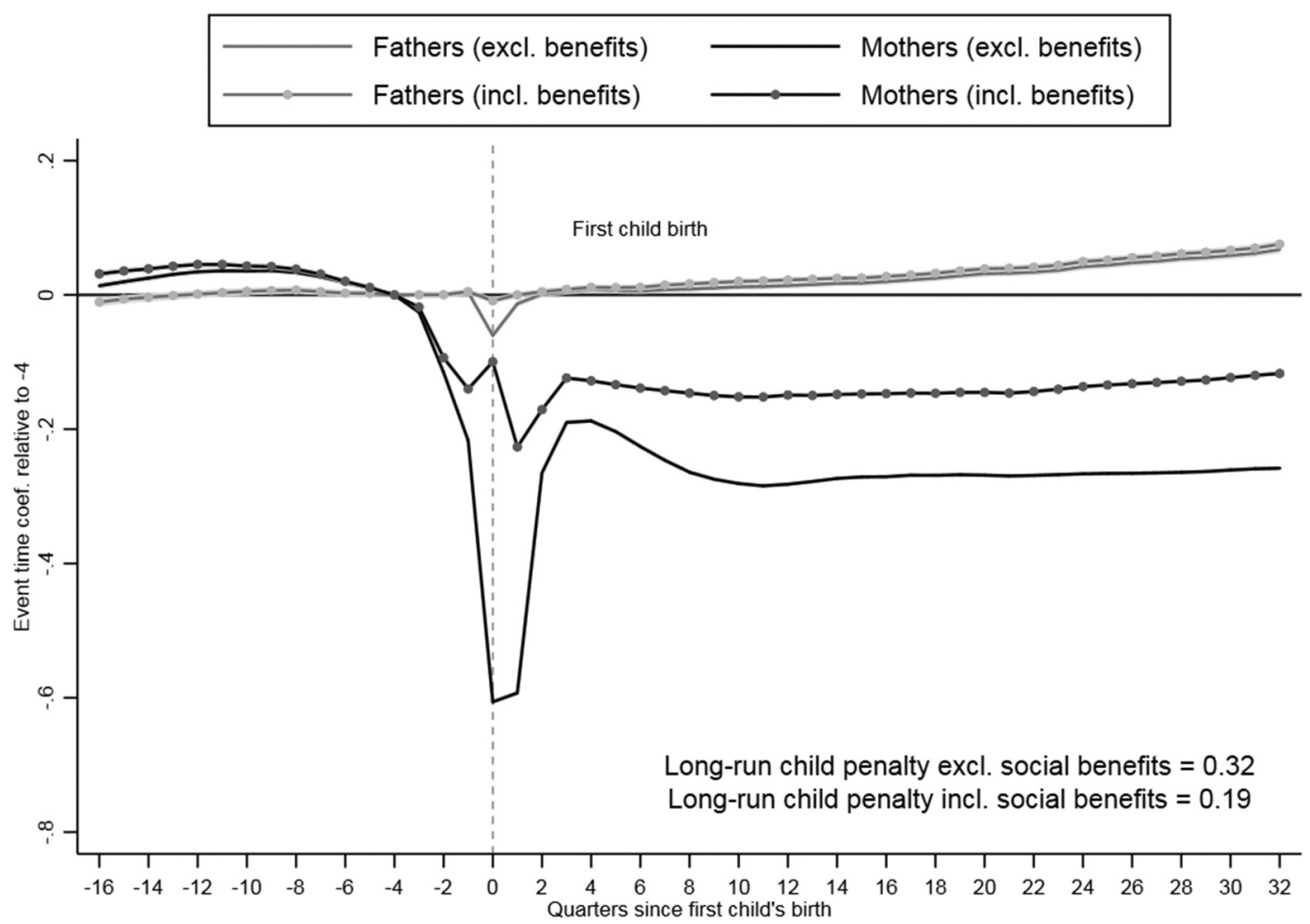

Figure A1. Impacts of children before/after social security transfers. Note: The shaded $95 \%$ confidence intervals are based on robust standard errors. Social security transfers include earnings-relatedmaternal allowance for a max. of 90 days, earnings-relate paternal allowance for a max. of 7 days, flat-rateparental allowance (available to both parents) for a max. of 4 months, as well as child benefits until the child turns 18 years old. 

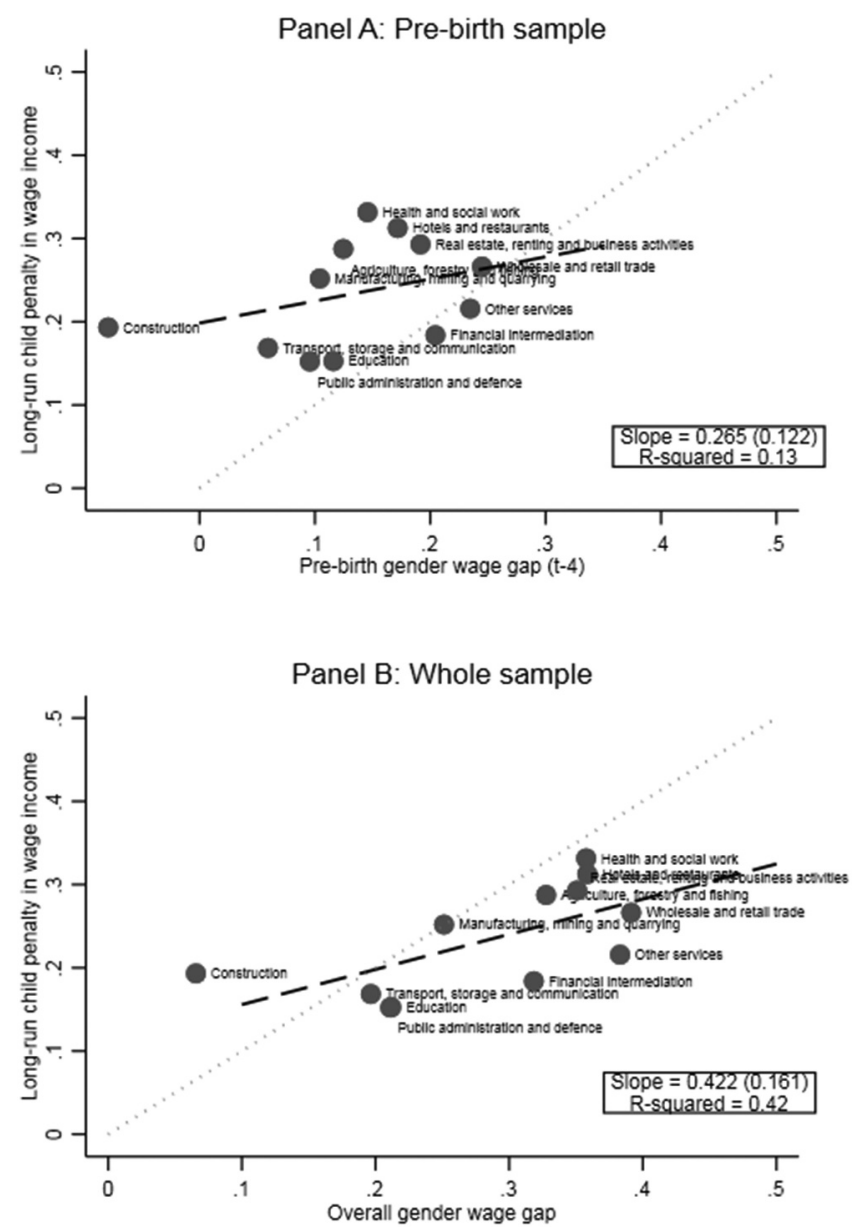

Figure A2. Long-run child penalties and within-sector gender wage gap. Note: The $x$-axes show the within-sector gender wage gapone year prior to the birth of the workers' first child (Panel A), as well as for a complete sample of workers at any stage of family formation (Panel B). The figures also display a linear trend, whose slope is reported with standard errors in parentheses. 